\title{
Mapping Industrial Systems - a supply network perspective on enabling technologies, processes and actors
}

\author{
Dr Jagjit Singh Srai \\ Centre for International Manufacturing, Institute for Manufacturing, \\ Department of Engineering, University of Cambridge CB3 OFS
}

\begin{abstract}
As part of the debate on future manufacturing competitiveness, research in Emerging Industries (EIs) has captured the keen attention of academics, industrialists and policy makers. Whilst technology roadmaps provide key perspectives focussed on technology development, effective mechanisms to capture and analyse the development of the industrial supply chain, crucial for commercialisation, remain a challenge. Indeed, these industrial systems are typically complex, and are not readily described by a single viewpoint and in this research we specifically address the need to better understand how supply networks (SNs) that support EIs might be systematically captured and visualised in order to support subsequent analysis of future evolution paths.
\end{abstract}

This paper develops a multi-layered multi-stage mapping approach to explore the characteristics of emerging industry supply networks (EI SNs), and how enabling production technologies and supply chain processes are supported by institutional, industrial and supply network actors. The mapping methodology involves the systematic capture of material transformations, enabling product and process technologies, and the actors, both institutional and industrial that might facilitate industrial development.

A key research challenge was to extend traditional methods of SN mapping and value chain analysis that typically adopt a narrow focal firm perspective of a firm's supply network, to also include key institutional, and other industrial system actors that form part of the wider industrial ecosystem. An industrial ecosystem mapping methodology was therefore developed that integrates and extends value chain analysis with SN configuration mapping, applied to a broader industrial systems context. The methodology is refined through application in selected EI sectors to demonstrate the usability and utility of the approach and its potential for future cross-case comparison studies.

\section{Background and Research Objectives}

The structural analysis of industries (Porter 1983, Dicken 2003), and the performance of clusters (Porter 1998, 2000) has largely focused on mature industries where change is a relatively long term phenomena. More dynamic industries, such as the evolution of the computer industry (Jacobides et al 2007), and the development of industrial networks in general (Karlsson 2003) have focused on macro level structural changes. In the case of Emerging Industries (EI) which have captured the interest of academics, industrialists, and policy makers as potential providers of new sources of wealth creation, the need to understand the industrial landscape (often unfamiliar to the industrial actors themselves) poses a particular challenge.

The mapping of industrial emergence from a supply network perspective requires the ability to capture changes in technology, but also changes in industry and SN structure, and their impact on the dynamics of production and supply. The dynamic nature of these complex industrial systems, requires consideration of SN structural reconfiguration (e.g. Srai and Gregory 2008) but extended to capture wider industrial and institutional actors, and operating model adjustments in terms of new activities and processes (Srai and Alinaghian 2013) and their consequent impact on material, information and value flows. This may lead to shifts in relative costs (Porter 1980), and new product, service and/or value propositions.

Another complication is the mapping of EI SNs is that there are often multiple technology platform 
developments that may co-exist in the market place. With product life cycles in EIs being typically short, as new product generations enter the market, there is a requirement to map through the material transformation process from raw materials to final product to understand the role of alternative production technology processes. From a SN perspective, uncertainty therefore lies in both material/intermediate supply and final product demand. This coupled with high productchurn/clockspeed will require mapping to be a structured, repeatable task if EI SNs are to be analysed over time periods to capture evolution paths. Utterback (1994) introduced terms that capture traditional evolution pathways, from nurture to maturity. More recently, academics have questioned, in the age of rapid technological change and innovation, whether industries will typically reach maturity (MacCarthy et al 2016) or whether they are likely to face continued reconfiguration.

In order to explore how supply networks evolve in support of EI development, the research will need to develop mapping tools, techniques and assessment frameworks that capture these macro and micro level interactions. Consistency of data collection methods will also facilitate standardisation of visual representation, vital for subsequent cross-sector comparisons.

This paper is structured as follows, Section 2 sets out the research challenges and the research question to be addressed. Section 3 identifies the research approach adopted, involving a multilayered multi-stage industrial 'systems' mapping technique that can capture enabling production technologies, supply network processes, and actors within EI SNs. Section 4 examines relevant literature to inform the development of the industrial system mapping technique, identifying relevant attributes of existing SN configuration mapping and analysis techniques. Elements of these mapping approaches are then selectively integrated to capture the EI SN context. Sections 5 and 6 set out the development of the mapping framework and the selection and application of cases studies to refine the framework. Section 6 in particular describes through exemplification the mapping process used to better understand the inter-firm relationships between institutional, industrial and SN actors within these dynamic industrial systems. Sections 7 discusses the results and output generated, and using examples from the case studies, the utility of the approach. The paper then concludes, together with some final perspectives for future research opportunities.

\section{Research Motivation}

The motivation for this research is to address a gap in current analytical capability regarding the mapping and visual representation of EI SNs, that as part of an integrated set of techniques, capture material transformations, enabling production technologies, and take account of the broader industrial system perspective covering both industrial and institutional actors. The development of an integrated methodology for mapping industrial emergence across the SN in a consistent and repeatable manner should enable improved understanding of enablers of industrial emergence. Whilst there is a body of literature on the technology development aspects of particular industries, and complementary work on the environmental, economic and fiscal contexts that have allowed them to develop, there is more limited understanding on industrial and supply network evolution (MacCarthy et al (2016)).

Secondly, few studies have considered cross-sector perspectives of EI SNs, restricting their contributions to either sector, or sector and country specific contributions. This together with the different methodologies used in their respective analyses, potentially restrict their findings to the particular industry contexts in which they are observed. This leads to a requirement in this research to develop a methodology that can be applied in a consistent manner to capture the SN of an EI together with its broader industrial system, as defined by Institutional and Industrial players who have a major role in the industrial development of the sector. In this context we might position the research aims in the form of a research question as 'how to map EI SNs in a consistent manner that can capture relevant operational elements of the broader industrial ecosystem to facilitate sector and cross-sector analysis?' 


\section{Research Approach}

The research approach involved a preparatory phase which required identifying relevant industrial system and supply network mapping dimensions. This involved a literature review on methods used for mapping SN configuration, from both the academic and practice literature to identify the mapping dimensions of interest. These dimensions were then used to explore a complex multi-product industrial system to enable mapping methodology development, identifying relevant organisational groupings within Institutional, SN and other (non-SN) Industrial actors that support industrial emergence. The approach would be used to inform the development of a series of industrial system mapping frameworks that collectively would provide visual representation of the industrial system. Applying these mapping frameworks over time periods, these outputs can provide a focal-firm supply network centric perspective of industry and supply network evolution, and thus representing a necessary addition but complementary asset to the more traditional technology and product road mapping activities.

Due to the complexity of the industrial system and SN configuration analysis, and the context rich nature of industrial emergence, the case study method was chosen to develop the process, and inform the nature of the target data. The development of these industrial system analysis and mapping frameworks, using the focal-firm based supply network centric case study method is discussed later in Sections 5 and 6.

\section{Literature Review on Methods for Industrial System Mapping}

A review of the literature on international industrial networks, specifically on approaches to industrial network/value chain mapping and analysis that adopt a supply network centric perspective was conducted, and is summarised in table 1. These mapping approaches and dimensions were used to inform the development of an EI SN mapping process, one that captures material transformation from raw material substrates to intermediates and final product, the enabling production processes and technologies used, and the participants, in terms of industrial and institutional actors. The integration of these EI SN elements as part of a systematic mapping methodology provides a basis for consistent visual representation and analysis.

Table 1. Summary of industrial supply network/value chain mapping techniques in the literature

\begin{tabular}{|c|c|c|c|}
\hline Type & Objective & Emphasis & Reference \\
\hline Functional Map & Process Mapping & Product \& Information flows & SCOR '06 \\
\hline Tier $1 \& 2$ Actors & Network Structure & Relationships, Complexity & Lambert et al '98 \\
\hline Tier $1 / 2$ Suppliers & Supplier Process Map & $\begin{array}{l}\text { Supplier role, relationships } \\
\text { (hard/soft) }\end{array}$ & Choi \& Hong '02 \\
\hline Process Flows & Activities, Mechanics & Firm roles, leaders, push-pull point(s) & OR fields \\
\hline Product Shape & Network Shape & Classification & Slack et al '95 \\
\hline Service & Thru-Life Management & Life cycle, design authority, services & Slack '05 \\
\hline Value Stream Maps & Value added/lost & Relative cost, quality, waste... & Hines \& Rich '97 \\
\hline Value Network Activity Maps & Network Actor identification & Activity mapping & Srai \& Alinaghian '13 \\
\hline Full Supply-Chain & Descriptive & Academic, conceptual & $\begin{array}{c}\text { New \& Payne '95, } \\
\text { Jagdev \& Thoben '01 }\end{array}$ \\
\hline Lean Mfg Map & Component Flow & Lean/inventory reduction & Rother \& Shook '99 \\
\hline Reverse Log's/Service & Directional Flows & Reverse Logistics \& repair & Blumberg '99 \\
\hline Geometry & Network flow/logic & Alternative routes/options & Fine '98 \\
\hline Organisational & Organisation Network & Co-ordination & Bartlett \& Ghoshal '89 \\
\hline Geographic & Geographical Spread & Co-ordination & Porter '86 \\
\hline Changing Ind. Structure & Industry Dynamics & Changing actor-scope profile & Jacobides et al '07 \\
\hline
\end{tabular}




\begin{tabular}{c|c|c|c|} 
Supply Network Configuration & Supply Network Design & Structure, dynamics, relationships & Srai \& Gregory '08 \\
\hline GVC Governance Models & Governance, Value capture & Governance & Sturgeon \& Gereffi '08
\end{tabular}

In evaluating these mapping techniques from the literature, the following attributes of interest were identified as relevant to mapping industrial systems and categorised as follows;

- Flows between actors; Financial flows, Material flows, Information flows

- Processes, activities: value-add necessary activities versus waste-unnecessary motion

- Dynamics, push-pull decoupling point, component flow, directional flows

- Network structure, network shape, network flow/logic, co-ordination (changes in)

- Network boundary (scope): firm or network level; regional or national:

- Geographical spread, spatial perspectives, location impacts

- Relationships between Network actors (hard/soft), Network roles, design authority

- Product category breadth and/or service scope; through-life value management, product life cycle

The task of mapping itself can be extremely resource intensive and requires selective application of these mapping categories to avoid unnecessary data capture and complexity. The focus of the mapping activity thus requires alignment between mapping objectives, dimension attributes and granularity of data capture selected and the network scope of the exercise, as exemplified in Table 2.

Table 2. Alignment between mapping focus, dimension attributes and scope of data capture

\begin{tabular}{|l|l|l|}
\hline Primary mapping focus & \multicolumn{1}{|c|}{ Map attributes } & \multicolumn{1}{|c|}{ Scope of data capture } \\
\hline $\begin{array}{l}\text { external context and } \\
\text { orientation for given } \\
\text { product/technology }\end{array}$ & $\begin{array}{l}\text { geographic context, } \\
\text { defining product and } \\
\text { network boundaries }\end{array}$ & $\begin{array}{l}\text { geographic region, relevant tiers only, relevant } \\
\text { firm or strategic business unit or product family or } \\
\text { platform technology }\end{array}$ \\
\hline supply network shape & $\begin{array}{l}\text { Network tier structure, } \\
\text { upstream \& downstream }\end{array}$ & low to moderate detail on network structure \\
\hline $\begin{array}{l}\text { strategic competitive } \\
\text { capability focus }\end{array}$ & $\begin{array}{l}\text { operational processes and } \\
\text { organisational routines }\end{array}$ & $\begin{array}{l}\text { material transformation processes, SN processes + } \\
\text { NPD processes + service delivery processes }\end{array}$ \\
\hline $\begin{array}{l}\text { Focal firm nodes and } \\
\text { network linkages }\end{array}$ & firm centric; network wide & replenishment, innovation-life cycles \\
\hline
\end{tabular}

\section{Development of Mapping Frameworks}

\section{Value Chain Mapping \& Supply Network Configuration Analysis}

The industrial system mapping approach builds on techniques developed in mapping SN configurations (Srai and Gregory, 2008), across the manufacturing value chain (Srai and Shi, 2008, Srai and Christodoulou 2014). In these studies, the supply network configuration has been defined as "that particular arrangement or permutation, of the supply network's key elements including, the "network structure" of the various operations within the supply network and their integrating mechanisms, the flow of materials and information between and within key "unit operations" the "role, inter-relationships, and governance" between key network partners, and the "value structure" of the product or service delivered". Within this definition the four elements which constitute the foundation of the configuration are:

- Supply network structure; network tier structure and shape, composition, ownership, levels of vertical and horizontal integration, location, co-ordination, manufacturing processes, optimum sequence, complexity, flexibility, etc 
- Material and Information Flow; both intra- and inter-key unit operations; value and nonvalue adding activities, process steps, optimum sequence, levels of flexibility, network dynamics (e.g. replenishment modes), infrastructure, and enabling IT systems

- Relationships and Governance; the role, inter-relationships, and governance between key network partners; the nature of these interactions or transactions, number, complexity, partner roles, governance and trust

- Product/Service value-structure; product composition and structure (including components, sub-assembly, platforms, modularity), product replenishment mode (e.g. is the product maketo-stock, make-to-order, configure-to-order), product variety (SKUs), products as spares, and through-life support and services

These configuration mapping approaches were used to inform the development of the mapping frameworks to capture EI SNs, requiring their further development to capture industry system level actors (institutional, industrial support as well as product supply chain actors) and the linkages between them. This development of SN mapping to the industrial system level was a key requirement for the consistent representation and visualisation of industrial systems that adopt a supply network centric perspective.

Two industrial systems were selected to prototype, test and develop the mapping frameworks in order to inform the operationalisation of the mapping activity and development of the generic mapping templates. Industrial Biotechnology was selected for this exploratory study as the sector supports a feedstock based 'process' industry with multiple product categories emerging from a single technology platform. It thus provides the requirement for mapping tools that explore substrate production process - intermediates production, a platform technology that serves multiple end uses. Photovoltaics was identified also as a target exploratory case due the co-existence of multiple product generations, with multiple technology platforms, that largely serve a single market, energy.

The UK Industrial Biotechnology (IB) and Global Photovoltaics (PV) sectors were used to develop the mapping framework as between them they meet the criteria of

- technology defined sectors (rather than product/market driven definitions)

- recognised emerging technologies

- have different geographical scope, national and international, to test generalisability/scalability of the process

- both IB and PV have multiple technologies within their process options

- alternative technology options co-exist in the market place providing rich opportunities and challenges in mapping but also provide potential opportunities for looking at evolution between one technology type/generation

- in the case of IB, the sector supports multiple end user product sectors, whereas PV is largely a single sector energy solution, again providing potential for generalizability

The integration of the methods outlined above, resulted in an industrial system level mapping framework (Figure 1) which served as a generic template for mapping EI SNs, enabling a key goal of the research, a consistent method of analysis to enable subsequent cross-sector comparison. The section below describe each of the five stages in the development of this mapping framework, including its application and refinement in the selected industrial case study. 


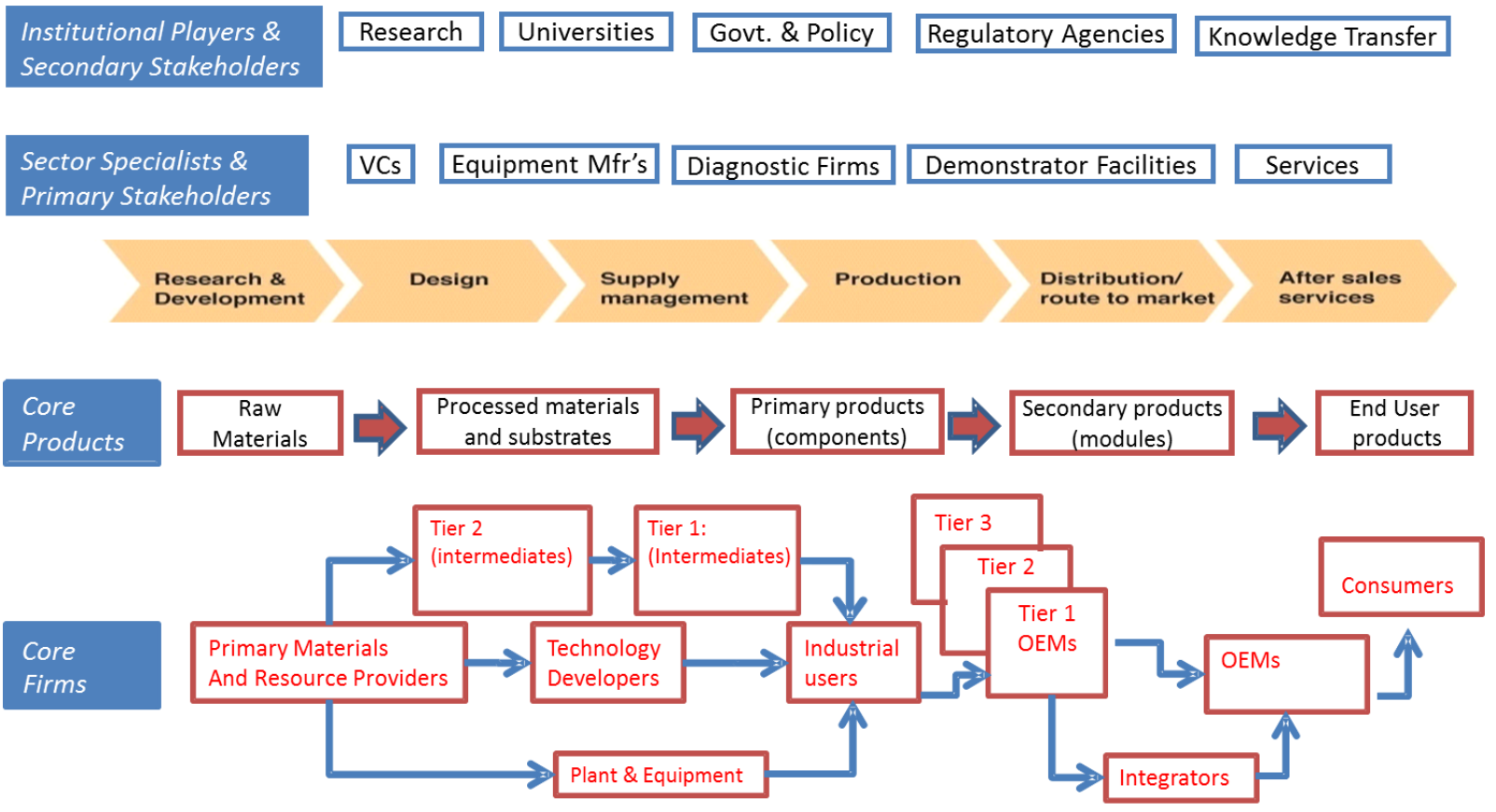

Figure 1 - Generic Industrial Systems Mapping Framework

The industrial systems mapping framework was then used to explore the role supply networks play in emerging industries. First this requires the capture of industry structure at a broad industrial systems level, followed by capturing the current structure of the supply network, and finally exploring alternative future supply network configurations within the industrial system, and their potential evolutionary phases.

The development of the five stage mapping approach is set out below, and for means of exemplification, each stage is schematically presented, using the UK Industrial Biotechnology sector as the example case.

\section{Five stage mapping approach and Findings}

Industrial system context and structure mapping, involved focal firm case-study investigations with actors from each of the main product categories, with focal-firm case-selection based upon their central role in the value chain.

Respondents from focal-firms, informed the identification of various actors (Institutional, Industrial and $\mathrm{SN}$ ) relevant to the industrial emergence dimensions presented to them. In addition they were requested to explore stages of SN evolution within the EI systems, from a past or nascent product stage, through to their current stage of emergence, and consider potential future stages of industry maturity. This narrative was then tested against the dimensions in Table 1, in terms of how well they capture or otherwise their actual and anticipated SN evolution. These outputs, arising from these complementary methods, were used to generate an understanding of key enablers of emergence of each industrial system studied.

The 5 stage process described below, involving key Institutional, Industrial and supply chain actors/stakeholders, used a pre-defined mapping structure. The process involves secondary data sources to be identified, followed by primary data collection using semi-structured interviews with recognised experts. Common structure enables effective cross-sector analysis. 
The five stage process, summarised in Table 3 and set out below in Section 6.2-6.5. Due to limitations of space the preliminary stage outputs for IB only are presented to describe each step with a summary of the final integrated output included for both IB and PV exploratory cases.

Table 3. Five Stage Mapping process - objectives, outputs, examples

\begin{tabular}{|c|c|c|c|}
\hline Stage & Mapping objectives & Outputs & Industrial Example \\
\hline $\begin{array}{c}\text { Stage 1: Mapping Sector Institutional } \\
\text { Actors }\end{array}$ & $\begin{array}{l}\text { Identifying relevant Sector } \\
\text { Institutional Actors }\end{array}$ & $\begin{array}{l}\text { Sector Institutional Map with identified } \\
\text { actors against stadardized categories }\end{array}$ & Figure 2 \\
\hline $\begin{array}{c}\text { Stage 2: Mapping SN wide Production } \\
\text { Processes }\end{array}$ & $\begin{array}{l}\text { Capturing material conversion } \\
\text { production processess }\end{array}$ & $\begin{array}{l}\text { Production Processes Map identifying } \\
\text { conversion (physical/chemical/bio) } \\
\text { production processes and unit operations }\end{array}$ & Figure 3 \\
\hline $\begin{array}{l}\text { Stage 3: Mapping SN wide Material } \\
\text { transformations }\end{array}$ & $\begin{array}{l}\text { Capturing material } \\
\text { transformations }\end{array}$ & $\begin{array}{l}\text { Mapping activity shows substrates, } \\
\text { intermediates and final products }\end{array}$ & Figure 4 \\
\hline Stage 4: Mapping SN Actors and Flows & $\begin{array}{l}\text { Capturing the flow of } \\
\text { materials, information, and } \\
\text { value across SN actors }\end{array}$ & $\begin{array}{c}\text { Supply network maps that shows the flow } \\
\text { of } 1 \text { )materials } 2 \text { )information } 3 \text { ) finacial } \\
\text { value between stanadrdised SN actor } \\
\text { types }\end{array}$ & $\begin{array}{l}\text { Figure } 5 \text { (SN actors \& } \\
\text { Sector specialists) }\end{array}$ \\
\hline $\begin{array}{c}\text { Stage 5: Consolidated SN perspective } \\
\text { Industrial Sector Map }\end{array}$ & $\begin{array}{l}\text { Integration of inputs from } \\
\text { previous stages }\end{array}$ & $\begin{array}{l}\text { Consolidated map that integrates } \\
\text { summary data from previous maps }\end{array}$ & $\begin{array}{l}\text { Figure } 6-I B \\
\text { Figure } 7-\mathrm{PV}\end{array}$ \\
\hline
\end{tabular}

\subsection{Stage 1: Mapping Sector Institutional Actors}

In the schematic (Figure 2), the generic framework is used to identify institutional actors, defined as those enabling organisations in terms of technology development, regulation, policy, specialist financial (sector specific venture capitalists) and specialist industrial actors (diagnostics, equipment manufacturers, services.

An example of completing a generic template can be the consideration of universities that are active in this area who act as important providers of IB innovation, working closely with companies with a challenge of improving substrates, equipment and processes and ensuring transfer for industry application. Key areas of research interest and active departments are pursuing Chemical polymerization, Modification of Biopolymer, Chemical transformation of renewable molecules, Biocatalysis and Fermentation (further details of these institutions are reported separately, Srai 2011).

This stage of the analysis enables sub-sector identification, and in the case of IB summarized as Biofuels, Food \& Drink, Personal Care and Fine Chemicals, with a catch-all 'Other' category used to capture niche product areas. This mapping analysis can be made more granular (e.g. see later, Figure 2 , production processes used, Figure 3 substrate maps that set out intermediate products) depending on the level of analysis required. 


\section{Industrial Biotechnology (UK): Institutional Players}

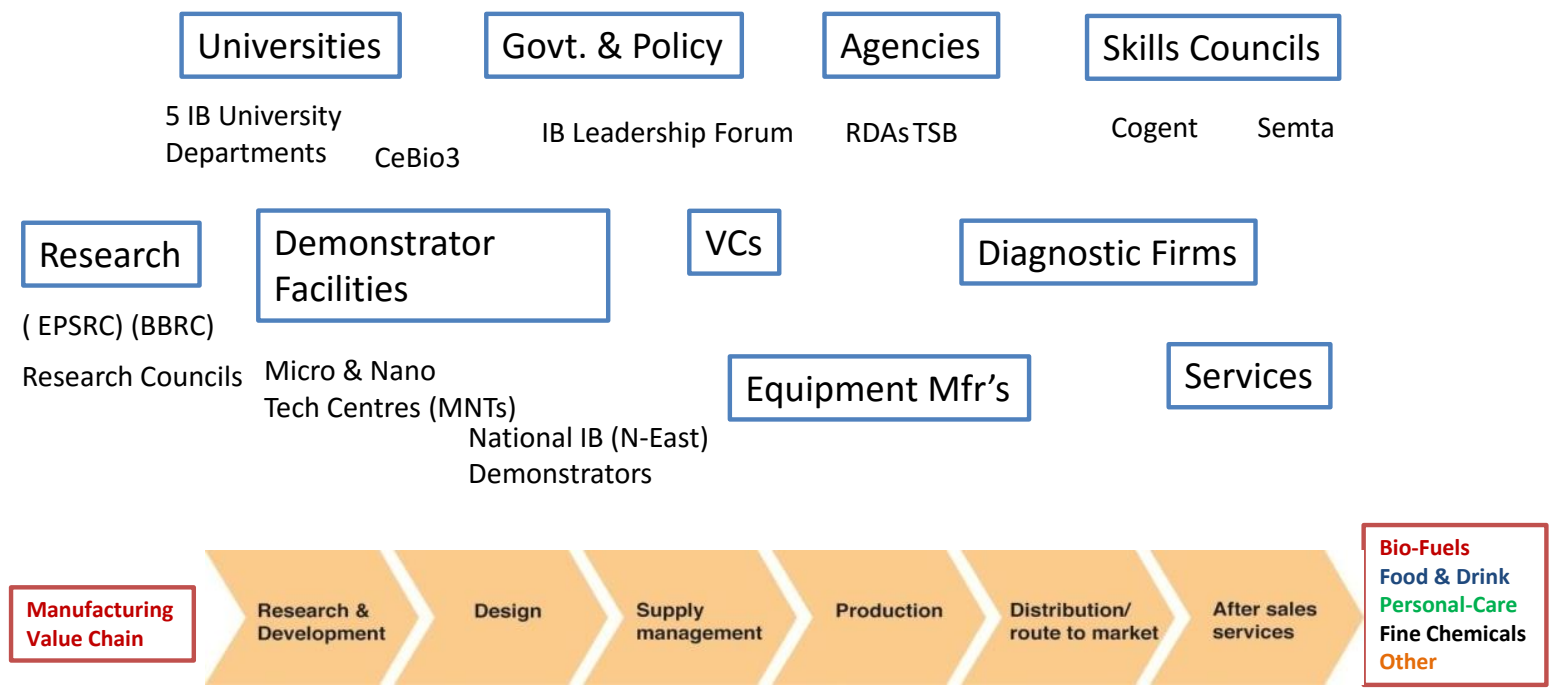

Figure 2 - Institutional Generic Map - Application to UK Industrial Biotechnology

\subsection{Stage 2: Mapping Supply Network Production Processes and Unit Operations}

The mapping of SN production processes and unit operations enables the analyst researcher ('cartographer') to consider the conversion steps involved in the transformation of materials into final products. This is crucial if within EI SNs production technologies are to be mapped - current and future - as it demonstrates the nature of the conversion processes (physical, chemical, biological) and there evolution. This stage of the mapping activity involves interviews with sub-product sector specialists, interviews grouped per product technology strand, based on supply chain production process and unit operations 'activity' mapping.

To exemplify the nature of the visual output Figure 3 summarises this output for the case of IB. The unit operations at each stage will include conversion activities, perhaps where new technologies may be deployed, but also logistical activities linked to materials and intermediate collection, storage and transport which may benefit from infrastructural and ICT developments.

Figure 3 demonstrates the utility of this mapping framework, setting out the logistics and unit operations activities and processes for each of the product categories in this EI. In this framework the importance of equipment providers as enablers of novel EI production processes is highlighted 


\section{Industrial Biotechnology (UK) Supply Chain Map: Production Process Stages and Unit Operations}

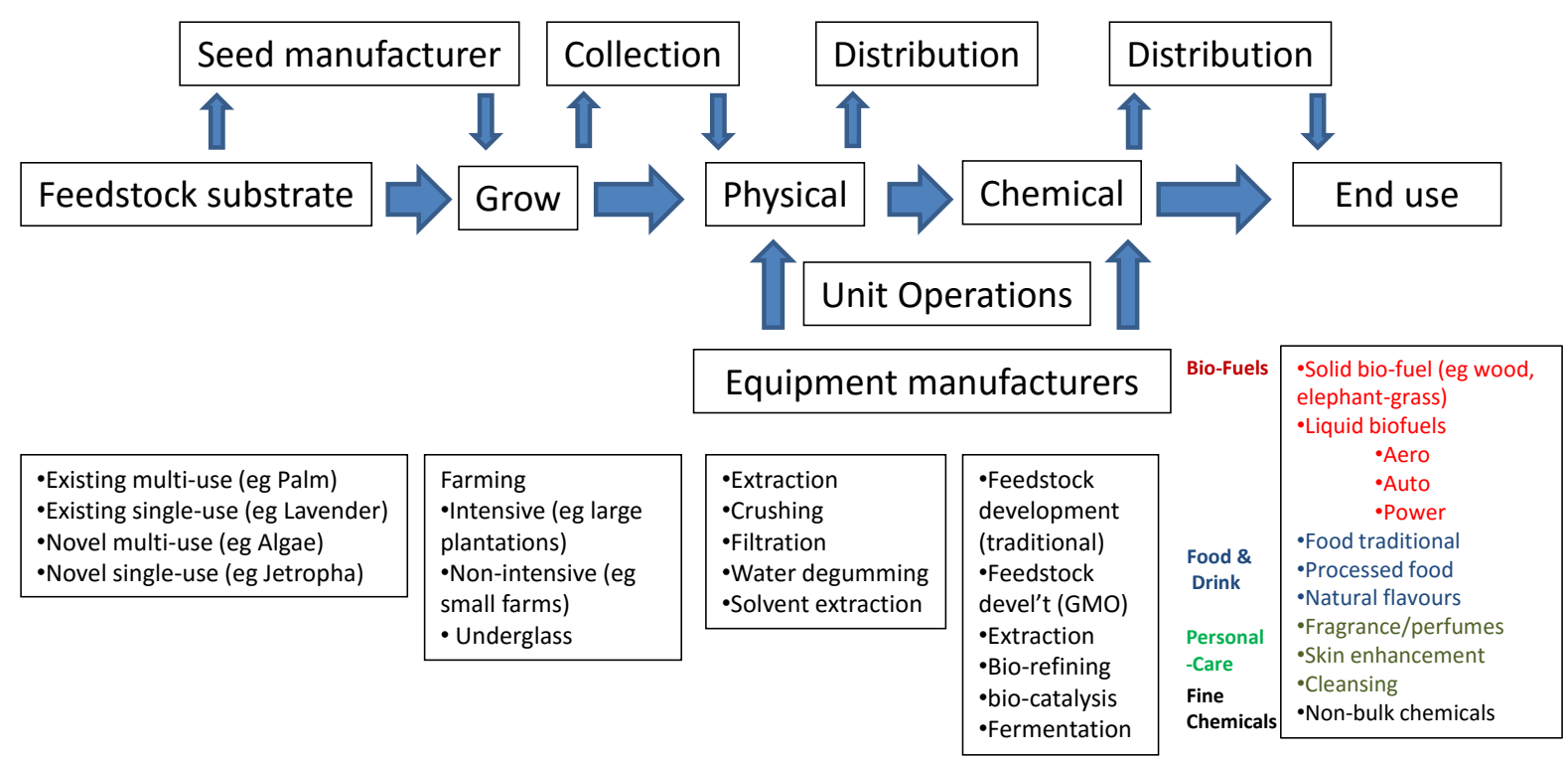

* Extraction may involve multiple separation processes e.g. purification, distillation, etc

Figure 3 - Production Processes and Unit Operations - applied to UK Industrial Biotech

\subsection{Stage 3: Mapping SN wide Material transformations}

The third stage of the mapping process focuses on the material flows within an EI SN. Here the information gathered in the previous step on conversion processes enables the structured mapping of material transitions; from substrates, through to intermediates, and finally through to finished products. Due to the SN wide perspective, the mapping process will likely involve secondary source and expert interviews used in combination to generate the level of granularity required.

In the specific IB case (Figure 4), specific bio-processing technologies apply, some aligned to particular substrates, resulting in technology specific intermediates and final products. The source data for generating the output for the example case of IB is reported elsewhere (Srai 2010).

The act of map generation shows how different feedstock substrates through alternative processing routes result in different intermediates for subsequent final processing. This information provides necessary input to SN actor identification in the subsequent stage of SN actor mapping. 


\section{Industrial Biotechnology (UK) - Substrates, Process Technology, Products}

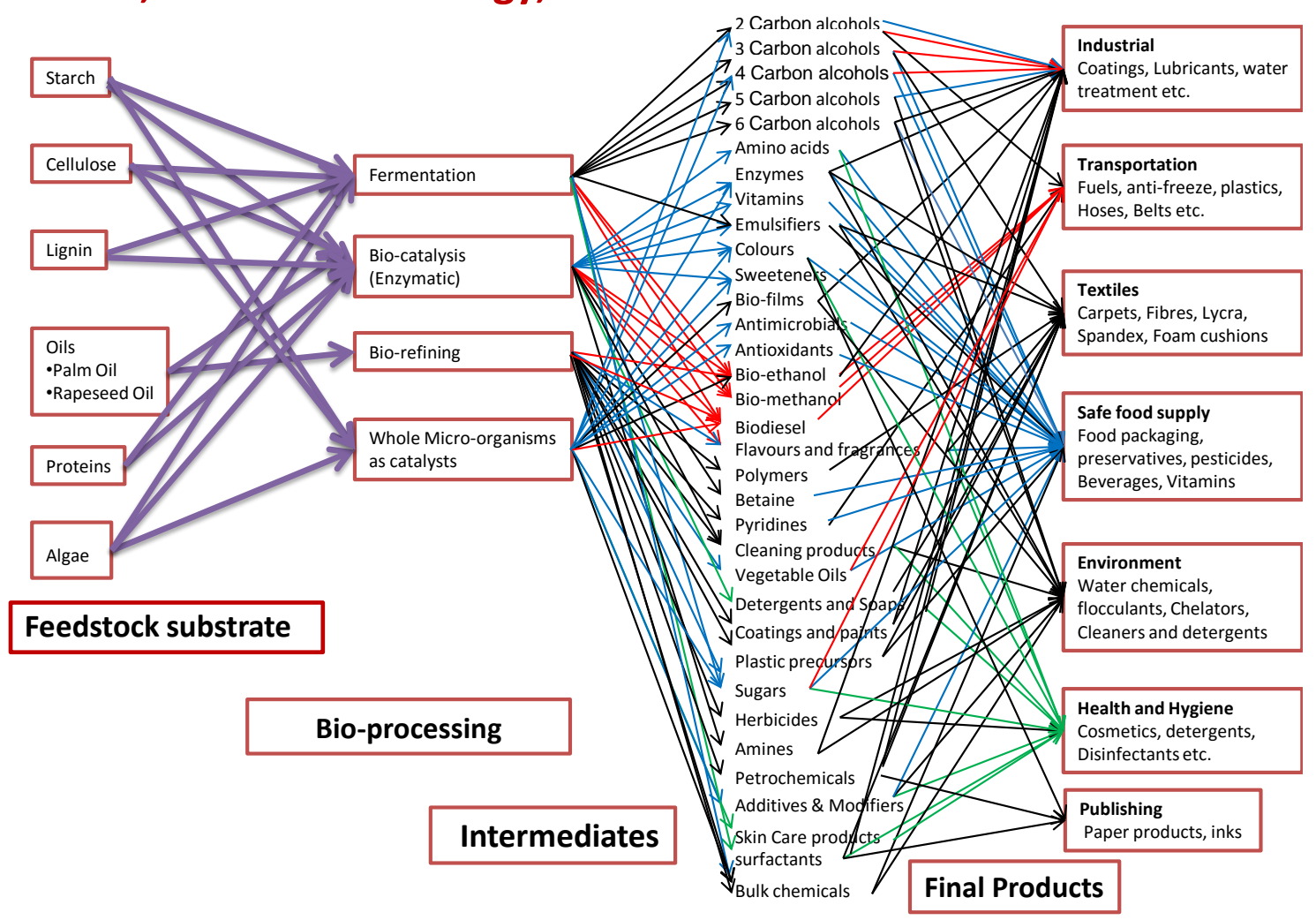

Figure 4 - Generic Industrial Systems Mapping Framework

\subsection{Stage 4: Mapping Supply Network Actors and Flows}

The final stage of map input generation is to identify the supply network actors involved in the industrial system. This may involve mapping the i) material ii) information and iii) value flows, as identified by transactions between SN actors. This map may take several forms, from a basic flow of materials map drawing on the bill of materials, an overlay of information flows, and finally the financial flows between SN organisations. Each of these introduce additional challenges in data collection and confidentiality, and may be more/less necessary depending on the desired utility of the map.

In the specific case of IB, Figure 5 summarises the output of this stage of the mapping process.

An alternative representation where a consolidated map of the industrial support actors is also included may be desirable. This involves visualisation of the Industrial and Supply Chain actors as a consolidated view of industrial actor/actor types (i.e. excluding Institutional actors) to understand the industrial community as a separate grouping. These may typically include the generic categories of diagnostic firms, equipment manufacturers and service providers who would self-recognise themselves as industrial players but are not part of the bill-of-materials supply chain but rather those that facilitate the production or servitization of manufactured goods. 
Main Supply Chain Actors and Industrial actor sub-groups
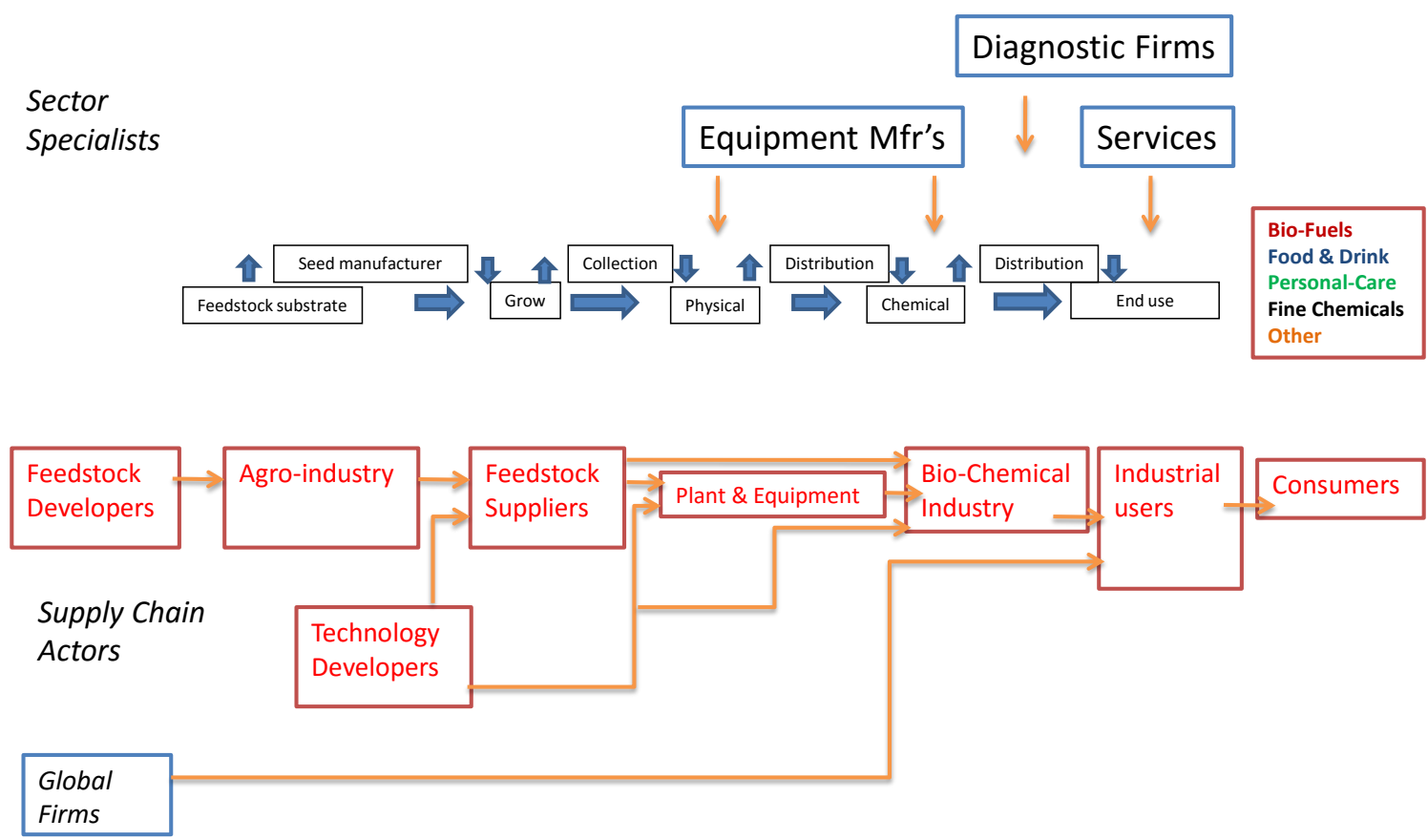

Figure 5 - Mapping Supply Chain Actor types - and Industrial Actor sub-groups - application example UK Industrial Biotechnology

\subsection{Stage 5: Industrial System Map: Synthesis of Preparatory maps into an integrated final output}

The final stage is the integration of the various outputs from previous stages of mapping activity to generate the consolidated output. Figure 6 and 7 respectively set out the data rich summary for the example cases in IB ad PV, demonstrating the ability to cover different production process and assembly-based technologies and geographical remits 
Industrial Biotechnology - UK

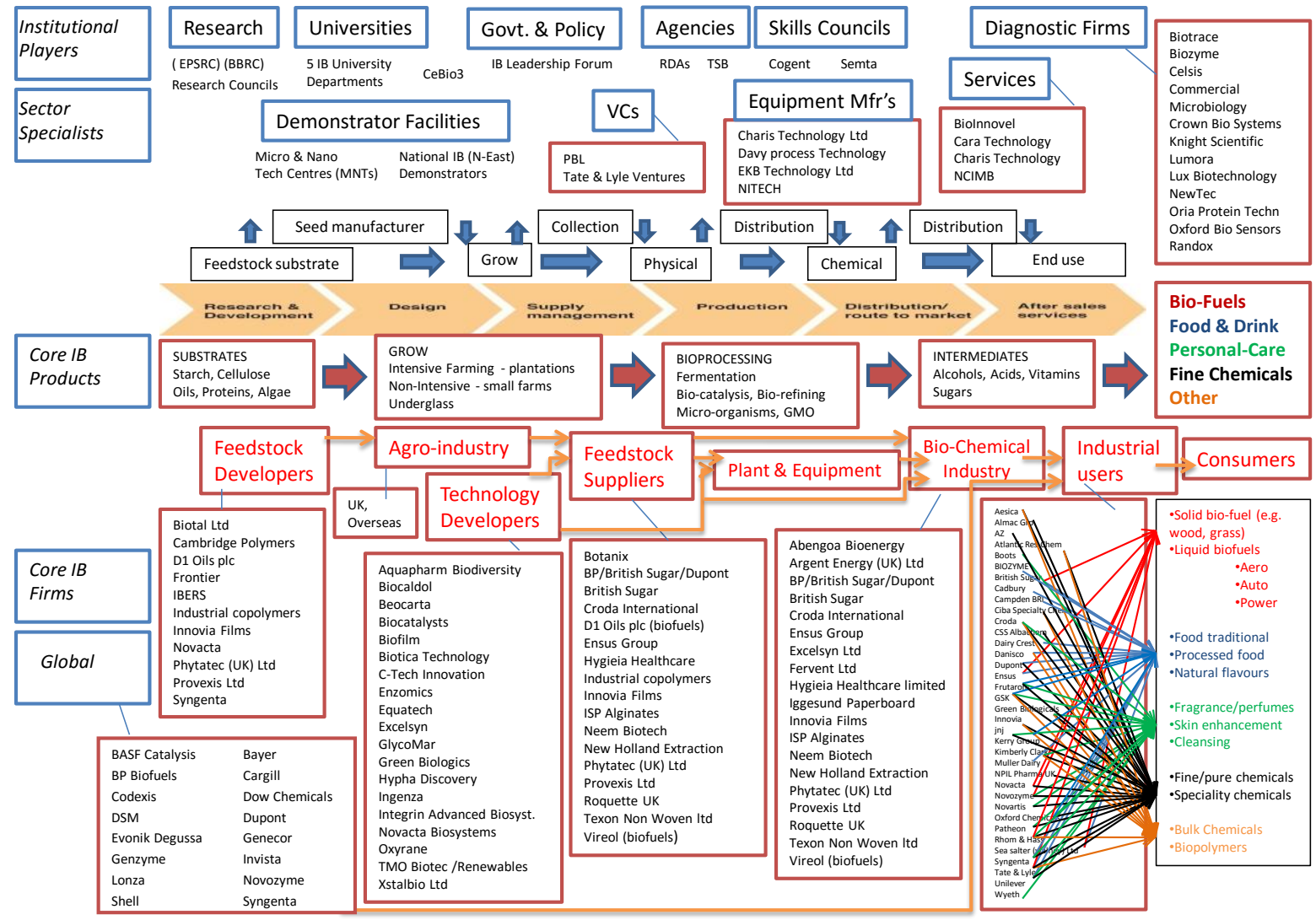

Figure 6 - Generic Industrial Systems Mapping Framework - applied to UK Industrial Biotechnology

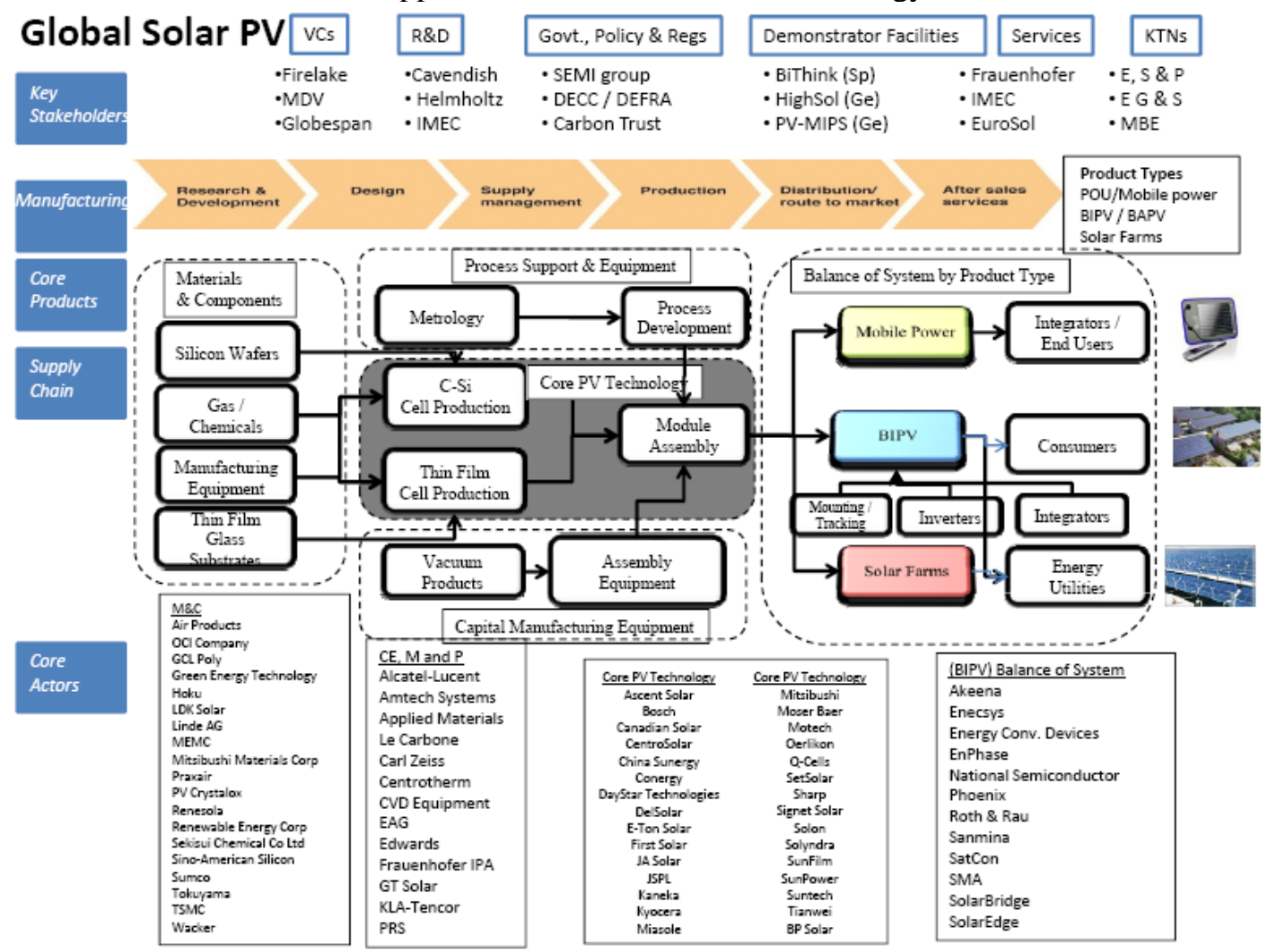

Figure 7 - Generic Industrial Systems Mapping Framework - applied to Global Solar Photovoltaics 
The mapping process for the global photovoltaic sector followed the same five stage process, with sector specific specialists used at each stage. Detailed data supporting the mapping of the photovoltaics sector (Kirkwood and Srai 2009, Srai and Christodoulou 2014)) are reported elsewhere, and formed part of an exploratory study into the development of the mapping process within a multitechnology, multiple product generations environment.

\section{Discussion}

The development of the mapping process and their output formats is a culmination of the in-depth applications of the generic mapping framework, as represented by the five stages of structured mapping activity, and associated generic templates covering two diverse technology intense sectors.

The two sector mapping examples have required transformations due to disruptive technology changes requiring a reconfiguration of their industrial supply network. The SN mapping techniques set out in Table 1, that have informed the mapping methodology reported here have included techniques widely used in 'discrete assembly' sectors such as automotive, aerospace, maritime shipbuilding, and 'process based industries' such as food, pharmaceuticals and textiles (Srai and Christodoulou 2014). In this paper we report on the two studies that have informed the development of the industrial sector mapping process. This paper sets out the core mapping process that allows a retrospective assessment of the utility of the mapping methodology resulting in a consistent representation. The standardization of the mapping process and common visualisation templates has enabled, at a macro-level future cross-sector comparisons. The maps provide visualization of the outputs that provide the opportunity to identify at an institutional level critical institutional players and secondary stakeholders. From an industrials perspective, the mapping process allow mapping of $\mathrm{SN}$ actors, actor types. From and industrial SN dynamics perspective, the flow of materials, information and value between actors is captured.

To exemplify the utility of the outputs of the mapping process within a particular sector we can observe in the case of the IB supply dynamics, that these are influenced by three main drivers. Firstly in terms of the feedstock. Here the feedstock source and degradation rate can determine location of elements of the supply chain. Feedstock availability, variability and consistency are driven by natural conditions/harvest. Second in terms of production processes, these involve several intermediate stages, control of which requires new skills from the traditional chemical process industry with renewable/ agro-material supply chains having different SN characteristics than for example bioactive material supply chains. Finally intermediate manufacture involves collection, storage and distribution which may be complicated by degradation issues.

In terms of supply chain actors and inter-relationships, the maps can be used to understand the potential connections between different actors across the industrial value chain, and that despite many firms in the sector the continued importance of global industrial players who play a key role in both 'supply' and 'demand' of IB products. From a policy perspective, the high churn rate will drive significant M\&A and VC activity and that SMEs engagement with MNCs requires 'nurture' and support, albeit that the nature of relationship development /evolution requires individual case study and that regulation can drive/hinder development in this emerging sector.

Beyond individual industrial system level analysis, cross-case analysis is enabled using this standard methodology, to identify generic patterns of emergence from a SN perspective. Generic cross-sector insights may be used to explore whether particular SN configurations enable or frustrate industry emergence.

The PV example demonstrates how the co-existence of multiple technology generations can impact industrial SN evolution. Figure 8 provides some of the insights arising from the map generation process and utility of the industrial system maps created. 


\section{Photovoltaic - co-existence of multiple technology generations}

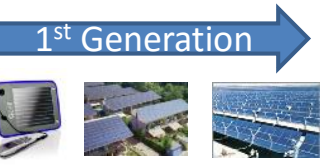

\section{First Gen}

Vertically integrated actors selling first generation modules largely to providers of large scale fixed solar power plants. Value Networks exhibit high levels of vertical integration with maturing industry characteristics. Weak business performance results in low dispersion and limited network development, typifying nascent value networks.

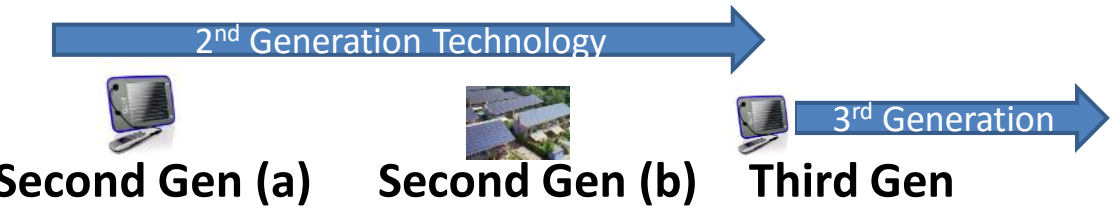

This reconfiguration pertains to

diversification into a more mature end-users, but using using second generation emerging technology which is sold to Building Integrated (BIPV) downstream actors. Diversification into more established end user markets results in more industrially mature and commercially stable partners.
Actors providing new delivery platforms through novel partnering strategies. This picture, of $2^{\text {nd }}$ generation technology used for large scale power products, also generates a somewhat fragmented network. The reasons for this again lie with disconnects between the maturity of the technology provision and the maturity of the partners and their networks.
Here $3^{\text {rd }}$ generation technology providers drive use in a mobile application products Here, many of the network partners are almost uniformly in the emergent phase, demonstrating the early nature of the technology production, where there is limited network maturity, and the product offering is driven by a small customer base

Figure 8 - Photovoltaic - co-existence of multiple technology generations

In summary, the review of supply chain mapping techniques and the specific methodology developed here, and its application in a number of emerging technology sectors, leads to the following observations on mapping industrial systems from a SN perspective.

Most importantly, it is vital to establish the intended use of maps and expectations on the granularity of the outputs required. In support of this it is desirable to undertake a rapid pilot study on a 'typical' sub-sector to clarify and 'test' approach, demonstrate style and content of outputs, and inform realistic scope and timeline schedule. When pursuing studies of selected sectors, the depth of the study may enable different levels of quantitative understanding of tier structure and dynamics and engagement. From a cross-case analysis perspective, this will determine the identification of generic and sector specific issues and challenges. From a practice perspective, the publication of maps can be used to inform industry and policymakers. In terms of exploring evolution trends, researchers might consider maintaining maps spanning several time horizons to track industry dynamics and emergence paths.

The methodologies developed in this research provide a basis for understanding current and future SN configurations, and industrial system in which it takes place, and the interconnections between actors that need to take place to enable industry evolution. Consolidated final output maps provide a conceptualisation of how this industry transformation is connected to technology and ultimately product enhancements.

\section{Conclusions}

A multi-layered multi-stage mapping approach is presented that captures the characteristics of EI SNs. The mapping methodology involves the systematic capture of material transformations, enabling product and process technologies, and the actors, both institutional and industrial that might facilitate industrial development. The mapping methodology involves the systematic application of frameworks that combine and extends existing supply and value chain analysis techniques with supply network configuration mapping approaches. The approach provides a basis for the consistent mapping of the 
supply networks of emerging industrial systems in terms of data capture, visual representation and an enabler for future research to support more robust cross-case analysis.

Two industrial systems of Industrial Biotechnology (IB) and Photovoltaics (PV) were selected to develop the supporting frameworks that underpin the mapping methodology as these sectors represent alternative and novel evolution paths providing distinct industrial contexts. The IB and PV maps define the key characteristics of these emerging industry supply networks and demonstrate the potential utility of the mapping methodology.

\section{Future Research and Limitations}

This work describes approaches and frameworks for mapping EI SNs. The principal opportunity this provides is to use the approach to explore multiple emerging industrial systems from a supply network perspective, in order to explore how EI supply networks can be nurtured and how they influence and shape the future evolution of emerging industries.

In terms of limitations, the current methodology development approach is limited by two, albeit indepth case studies. Further industrial system case studies can be usefully used to further test, refine and validate the mapping approach set out in this paper.

\section{Acknowledgements}

The authors would like to acknowledge the financial assistance provided by EPSRC, and our industrial collaborators who provided access to their organisations, supply network, industrial and institutional partners.

\section{References}

Awa H.O. (2010) 'Democratizing the new product development process', International Business Research, Vol. 3, No. 2, pp. 49-59.

Bartlett, C. A. and Ghoshal, S. (1989) 'Managing Across Borders: The Transnational Solution', Boston, Massachusetts, Harvard Business Press.

Blumberg, D.F. (1999) 'Strategic examination of reverse logistics and repair service requirements, needs, market size, and opportunities", Journal of Business Logistics, Vol. 20, No. 2, pp. 141-159.

Capra, F. (2002) 'The hidden connections - A Science For Sustainable Living', Harper.

Choi, T.Y. and Hong, Y., (2002) 'Unveiling the structure of supply networks: case studies in Honda, Acura, and Daimler Chrysler', Journal of Operations Management, Vol. 20, No. 5, pp. 469-493.

Choi, T.Y. and Krause, D.R. (2006) 'The supply base and its complexity: implications for transaction costs, risks, responsiveness, and innovation', Journal of Operations Management, Vol. 24/25, pp. 637-652.

den Hartigh, E., \& van Asseldonk, T. (2004) 'Business ecosystems: A research framework for investigating the relation between network structure, firm strategy, and the pattern of innovation diffusion'. In ECCON 2004, The Netherlands. pp. 1-38

Dicken, P. (2003) 'Global Shift: Reshaping the Global Economic Map in the 21st Century', 4th edition, London, Sage Publications Ltd.

Fine, C., (1998) 'Clockspeed - Winning Industry Control in the Age of Temporary Advantage', New York: Perseus Books.

Hines, P. and Rich, N. (1997) 'The seven value stream mapping tools', International Journal of Operations \& Production Management, Vol. 17, No. 1, pp.46-64.

Jacobides, M.G. and Winter, S.G. (2007) 'Entrepreneurship and Firm Boundaries: The Theory of A Firm', Journal of Management Studies, Special Issue on Entrepreneurship and the Entrepreneurship of the Firm, Vol. 44, pp. 1213-1241.

Jagdev, H.S. and Thoben, K.D. (2001) 'Anatomy of enterprise collaboration', Production Planning and Control, Vol. 12, No. 5, pp. 437-51. 
Kamath, N.B. and Roy, R. (2007) 'Capacity augmentation of a supply chain for a short lifecycle product: a system dynamics framework’, European Journal of Operational Research, Vol. 179, No. 2, pp. 334-351.

Karlsson, C. (2003). The development of industrial networks: challenges to operations management in an extraprise. International Journal of Operations \& Production Management, 23(1), 44-61.

Kirkwood, K. and Srai, J.S. (2009), 'Charting Industry Emergence from a Supply Network Perspective: the evolution of the photovoltaic industry, ICMR'09, Warwick

Lambert, D. M., Stock, J. R., et al. (1998) 'Fundamentals of Logistics Management', Boston; London, Irwin/McGraw-Hill.

MacCarthy, B., Blome, C., Olhager, J., Srai, J.S., Zhao, X., (2016) 'Supply Chain Evolution - Theory, Concepts, Science', International Journal of Operations and Production Management, DOI 10.1108/IJOPM-02-2016-0080

Moore, J.F. (1993) 'Predators and Prey: A New Ecology of Competition', Harvard Business Review, May.

New, S.J. and Payne P. (1995) 'Research frameworks in logistics: three models, seven dinners and a survey', International Journal of Physical Distribution and Logistics Management, Vol. 25, No. 10, pp. 60-77.

Porter, M.E. (1980) 'Competitive Strategy', The Free Press, McMillan.

Porter, M.E. (1983) 'Cases in Competitive Strategy', NY: Free Press.

Porter, M.E. (1986) 'Changing patterns of International Competition', California Management Review, Vol. 28, No. 2, pp. 9-40.

Porter, M.E. (1998) 'Clusters and the New Economics of Competition', Harvard Business Review, September-December

Porter, M.E. (2000) 'Location, competition, and economic development: local clusters in a global economy', Economic Development Quarterly, Vol. 14, No. 1, pp. 15-35

Rother, M. and Shook, J. (1999) 'Learning to See: Value Stream Mapping to Add Value and Eliminate Muda', Lean Enterprise Institute, Brookline, MA

Simchi-Levi, D. and Fine, C.H. (2010) 'Your next supply chain', MIT Sloan Management Review, Vol. 51, No. 2, pp. 17-25.

Slack, N. et al, (1995) 'Operations Management', Pitman Publishing, London.

Slack, N. (2005) 'Patterns of Servitization: Beyond Products and Service', University of Cambridge, IfM Publication

Srai, J.S. (2007) 'Global Solutions', Manufacturing, Vol. 86, No. 5, pp. 32-35.

Srai J.S., (2010) 'A Preliminary Map of the U.K. Industrial Biotechnology Supply Chain. University of Cambridge, Institute for Manufacturing: Cambridge U.K. ISBN: 978-1-902546-42-1

Srai J.S. and Alinaghian L.S. (2013) 'Value chain reconfiguration in highly disaggregated industrial systems: examining the emergence of healthcare diagnostics', Global Strategy Journal, Vol. 3, pp. $88-108$.

Srai, J.S., and Christodoulou, P., (2014). "Capturing Value from Global Networks; Strategic approaches to configuring international production, supply and service operations", University of Cambridge IfM Publication ISBN: 978-1-902546-30-8.

Srai, J.S. and Gregory, M.J. (2008) 'A Supply network configuration perspective on international supply chain development', International Journal of Operations and Production Management, Vol. 28, No. 5, pp. 386-411.

Srai, J.S. and Shi, Y.J. (2008) 'Understanding China's Manufacturing Value Chain', University of Cambridge IfM Publication, ISBN 978-1-902546-69-8.

Sturgeon, T. and Gereffi, G., (2008) 'Value Chains, Networks, and Clusters: Reframing the Global Automotive Industry', Journal of Economic Geography, Vol. 8, No. 3, pp. 297-321.

Technology Strategy Board Strategic Report, (2010) "Emerging Technologies and Industries: Strategy 2010-2013", available at: www.innovateuk.org, accessed 5th January 2011

Utterback, J.M. (1994) "Mastering the dynamics of innovation: how companies can seize opportunities in the face of technological change", Harvard Business School Press. 